\title{
Efeito da Temperatura sobre o Desempenho da Rã-touro \\ (Rana catesbeiana Shaw, 1802) ${ }^{1}$
}

\section{Mario Roberto Chim Figueiredo ${ }^{2}$, Claudio Angelo Agostinho ${ }^{3}$, Fernando da Costa Baêta ${ }^{4}$, Samuel Lopes Lima ${ }^{5}$}

\begin{abstract}
RESUMO - Este estudo foi realizado para avaliar os efeitos do ambiente sobre a performance de rã-touro (Rana catesbeiana Shaw, 1802), criada em gaiolas de fibra de vidro instaladas no interior de estufas climatizadas. Após um período inicial de 15 dias de adaptação às instalações, à temperatura constante de $25,0^{\circ} \mathrm{C}$, os seguintes tratamentos foram aplicados: temperaturas de 23,0;26,0;29,0;32,0; e $35,0^{\circ} \mathrm{C}$, por 30 dias, para rãs com $100 \mathrm{~g} \mathrm{PV}$ inicial; 24,$5 ; 26,0 ; 27,5 ; 29,0 ; 30,5 ; \mathrm{e} 32,0^{\circ} \mathrm{C}$, também por 30 dias, para rãs com $20 \mathrm{~g} \mathrm{PV}$ inicial; e a combinação das temperaturas de 26,0 e $29,0^{\circ} \mathrm{C}$ com os fotoperíodos de 8,12 e $16 \mathrm{~h}$ de luz a cada 24 horas, para rãs com $100 \mathrm{~g}$ PV inicial. Derivando-se as equações de regressão que explicam os efeitos de temperatura sobre o desempenho das rãs, estimaram-se melhores ganhos de peso à temperatura de 27,6 e $30,1^{\circ} \mathrm{C}$, para rãs com 100 e $20 \mathrm{~g} \mathrm{PV}$ inicial, respectivamente, com melhor crescimento a $28,2^{\circ} \mathrm{C}$, para as rãs de $100 \mathrm{~g}$ PV inicial, e a $29,7^{\circ} \mathrm{C}$, para as rãs de $20 \mathrm{~g}$ PV inicial. A temperatura interagiu com fotoperíodo nos seus efeitos sobre ganho de peso e crescimento corporal, peso e rendimento de carcaça, consumo de alimentos e conversão alimentar.
\end{abstract}

Palavras-chave: ambiente, crescimento, desempenho, fotoperíodo, rã-touro, temperatura

\section{Temperature Effect on Performance of Bull-frog (Rana catesbeiana Shaw, 1802)}

\begin{abstract}
This study was carried out to evaluate the environmental effects on bull-frog (Rana catesbeiana Shaw, 1802) performance, raised in fiber glass cages installed inside acclimatized incubators. After an initial period of 15 days of adaptation, at constant temperature of $25.0^{\circ} \mathrm{C}$, the following experimental treatments were applied: temperatures of 23.0, 26.0, 29.0, 32.0 and $35.0^{\circ} \mathrm{C}$ per 30 days for frogs with $100 \mathrm{~g}$ initial LW; 24.5, 26.0, 27.5, 29.0, 30.5, and $32.0^{\circ} \mathrm{C}$, also on 30 days, for frogs with $20 \mathrm{~g}$ initial LW; and the combination of the temperatures of 26.0 and $29.0^{\circ} \mathrm{C}$ with the photo periods of 8,12 and $16 \mathrm{~h}$ of 1 ight at every 24 hours, for frogs with $100 \mathrm{~g}$ initial weight. By deriving the regression equations that explain the temperature effects on the frogs performance, the highest weight gain was estimated at 27.6 and $30.1^{\circ} \mathrm{C}$ frogs with 100 and $20 \mathrm{~g}$ initial $\mathrm{LW}$, respectively, with the highest growth at $28.2^{\circ} \mathrm{C}$, for frogs of $100 \mathrm{~g}$ initial $\mathrm{LW}$ and at $29.7^{\circ} \mathrm{C}$, for frogs of $20 \mathrm{~g}$ initial $\mathrm{LW}$. Temperature interacted with photoperiod in their effects on weight gain and body growth, weight and carcass yield, feed intake and feed:gain ratio.
\end{abstract}

Key Words: environment, growth, performance, photo period, temperature, bullfrog

\section{Introdução}

É próprio das rãs, ectotérmicas, selecionarem temperaturas específicas em determinado ambiente (BRADFORD, 1984; WOLLMUTH et al., 1987), deslocando-se à procura do melhor conforto térmico. Naturalmente se sujeitam aos limites estabelecidos pelas variações sazonais de clima do local, uma vez que não fazem movimentos migratórios inter-regionais. As mudanças na temperatura ambiente são compensadas parcialmente pela aclimação, que pode alterar a temperatura letal, as taxas de vários processos fisiológicos (como taxa metabólica) e bioquímicos, as propriedades cinéticas de enzimas metabólicas e a temperatura a ser selecionada em determinado gradiente térmico (MILLER e ZOGHBY, 1986).

Nas criações intensivas, se as rãs não forem criadas em ambiente que propicie o melhor conforto térmico, não lhes restará a alternativa de se movimentar em busca das condições térmicas desejadas. Assim, seu desempenho estará comprometido, seja pela redução da ingestão de alimentos, seja pela impossibi-

\footnotetext{
${ }^{1}$ Parte da Tese de Doutorado em Zootecnia, do primeiro autor à Universidade Federal de Viçosa, Viçosa, MG - CAPES/CNPq. ${ }^{2}$ Professor Adj. da Fundação Universidade do Rio Grande, DOc., Lab. Aq. Continental, C.P. 474, 96201-900, Rio Grande - RS. ${ }^{3}$ Prof. Ass. Doutor do Dep. de Produção e Exploração Animal, FMVZ, UNESP. C.P. 560. 18618-000 - BOTUCATU - SP. ${ }^{4}$ Professor Titular da Universidade Federal de Viçosa, Dep. Engenharia Agrícola, 36571-000, Viçosa - MG. ${ }^{5}$ Professor aposentado da Universidade Federal de Viçosa, DBA, Ranário Experimental, 36571-000, Viçosa - MG.
} 
lidade de conversão do alimento ingerido em carcaça.

No Brasil, embora as condições de criação de rãtouro sejam consideradas muito favoráveis, existem diferenças regionais que resultam em dificuldades para produzir ou realizar pesquisas com essas rãs (LIMA e AGOSTINHO, 1992), especialmente em regiões onde existem restrições climáticas (FIGUEIREDO e MANGIALARDO, 1992).

A informação de que a temperatura ambiente de $40^{\circ} \mathrm{C}$ é ideal para promover o melhor desempenho de rã-touro (FONTANELLO et al., 1993) contrasta com o fato de que rãs da espécie Rana pipiens (para as quais se esperaria exigências semelhantes à rãtouro) podem sofrer até prolapso cardíaco em temperatura ambiente de 34 a $37^{\circ} \mathrm{C}$, por mais de 2 horas (CARLSTEN et al., 1983). A temperatura considerada máximo crítico térmico (MCT), de acordo com definição de Cowles e Bogert (1944) e Lowe e Vance (1955), citados por CARLSTEN et al. (1983), i. é, "o ponto térmico no qual as atividades motoras começam a se desorganizar e o animal perde a habilidade de escapar dessas condições que o levarão rapidamente à morte", varia , para Rana pipiens, entre 34 e $37^{\circ} \mathrm{C}$ (Seibel, 1970, citado por CARLSTEN et al., 1983), ou pode ser elevada para 38 a $39^{\circ} \mathrm{C}$, quando a temperatura se elevar lentamente (Cameron e Brownlee, 1915, citados por CARLSTEN et al., 1983) ou depois de exposição a ciclos diários de temperaturas mais elevadas (Hutchinson e Ferrance, 1970, citados por CARLSTEN et al., 1983).

O processo de termorregulação por aquecimento do corpo ao sol, utilizado pelos Amphibia, pode ser o responsável pela aceleração dos processos digestivos desses animais, no ambiente natural. (BRATTSTROM, 1979). Em criação de rãs confinadas, esses animais são privados do banho de sol, mas devem ser igualmente estimulados a comer e a manter ativa sua digestão para que se tornem produtivos.

BRATTSTROM (1979) sugere que sejam realizados estudos a partir de gradientes térmicos, usando compartimentos climatizados que permitam avaliar os efeitos do fotoperíodo, da aclimação e do metabolismo energético sobre o comportamento da termorregulação de rãs em cativeriro, com a finalidade de se conhecerem melhor os efeitos do ambiente sobre esses anfíbios.

Com a finalidade de avaliar os efeitos da temperatura sobre o desempenho de rã-touro, foram realizados três experimentos em seis estufas climatizadas artificialmente (FIGUEIREDO, 1996). Nesses experimentos procurou-se determinar os níveis de tolerância e as faixas de temperatura que proporcionam melhor desempenho à rã-touro (Rana catesbeiana SHAW, 1802).

\section{Material e Métodos}

Os experimentos foram realizados no Ranário Experimental da Universidade Federal de Viçosa, em uma sala climatizada, mantendo-se o ar ambiente em temperatura sempre abaixo da menor temperatura experimental. Foram utilizadas seis estufas climatizadas nas quais a intensidade de luz foi constante, de aproximadamente 500 lux.

No interior de cada estufa foram instaladas duas gaiolas do modelo descrito por FIGUEIREDO e MANGIALARDO (1992), previamente distribuídas ao acaso entre as estufas, sendo considerada gaiola 01 , a de cima e gaiola 02 , a de baixo. A temperatura no interior das estufas foi controlada por termostatos. A água, pré-aquecida de acordo com o tratamento de cada estufa, descia por gravidade, com fluxo regulado para cada gaiola.

O alimento constituiu-se de ração extrusada (comercial) com quantidades decrescentes de larvas de Musca doméstica, seguindo-se os procedimentos descritos por ALEIXO et al. (1984) e LIMA e AGOSTINHO (1984). As larvas foram cultivadas em larvários do Ranário Experimental da UFV e obtidas de moscários no mesmo local. Em todos os tratamentos o alimento foi servido ad libitum, uma vez por dia, entre as 15 e $16 \mathrm{~h}$, através de uma pequena janela $(15 \times 15 \mathrm{~cm})$ localizada na parte posterior de cada estufa (Figura 1).

As rãs foram marcadas cortando-se artelhos (MARTOF, 1953), salteando-se as unidades 2 e dezenas 40 (Figura 2), para não afetar seu apoio. A biometria consistiu em medir o comprimento total, da ponta do focinho até a cloaca (extremidade da coluna vertebral), utilizando-se paquímetro, e pesar todas as rãs, em balança eletrônica com sensibilidade de $1 \mathrm{mg}$ $(0,001 \mathrm{~g})$ e capacidade de $420 \mathrm{~g}$. O desempenho foi avaliado pelo ganho de peso e pelo crescimento das rãs no período.

Antes das biometrias, as rãs ficaram em jejum por 24 horas. Todas as rãs de uma gaiola eram colocadas num balde plástico de 100 litros, com tampa, que recebia um litro da mesma água que abastecia a gaiola, adicionando-se $1,0 \mathrm{~mL}$ de suplemento vitamínico comercial.

As sobras de ração foram coletadas em bandejas de alumínio enumeradas e secas em estufa, por 24 horas, a $55^{\circ} \mathrm{C}$. As sobras secas de cada gaiola foram pesadas, 


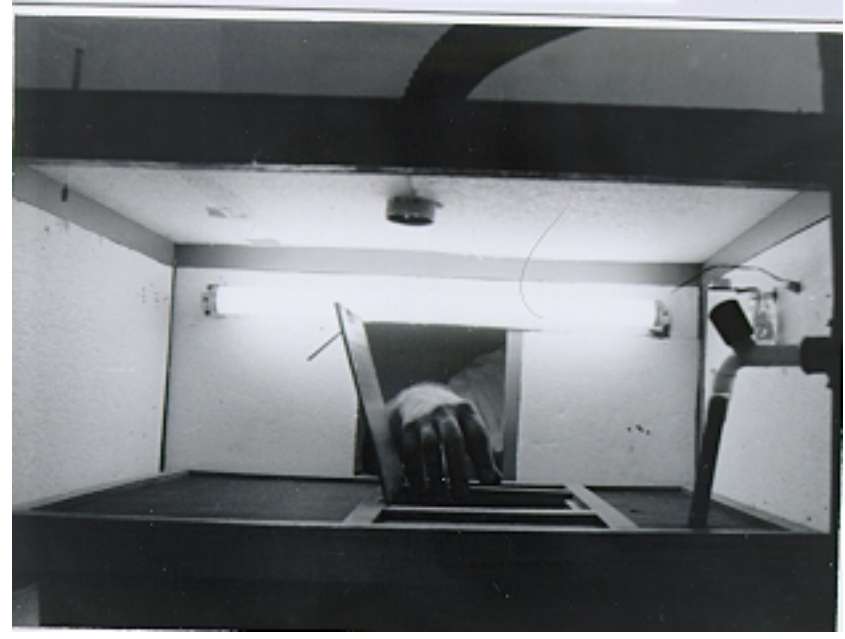

Figura 1 - Janela para observação e manejo das rãs dentro das estufas.

Figure 1 - Window to observation and handling of the frogs into the stoves.

após a temperatura entrar em equilíbrio com o ambiente.

O consumo de ração foi avaliado para cada gaiola, descontando-se as rãs mortas ou sacrificadas. Considerou-se conversão alimentar (CA) o incremento em peso observado para cada quilo de ração consumida.

Os resultados foram analisados pelo Sistema de Análises Estatísticas e Genéticas (SAEG) (EUCLIDES, 1983). Para as variáveis em estudo, os dados foram interpretados por meio de análises de variância e regressão.

\section{Experimento 01}

Para um período de 15 dias de adaptação, 240 rãs com peso médio inicial de 94,23 $\pm 12,03 \mathrm{~g}$ foram marcadas e distribuídas aleatoriamente entre as 12 gaiolas (vinte por gaiola). A temperatura foi mantida em $25,0^{\circ} \mathrm{C}$. Após este período, 180 rãs foram selecionadas de acordo com o peso vivo (descartando-se os extremos) e distribuídas aleatoriamente, quinze para cada gaiola.

Foram testadas seis faixas de temperatura: 20,0; 23,$0 ; 26,0 ; 29,0 ; 32,0 ;$ e $35,0^{\circ} \mathrm{C}$, aquecendo-se cada estufa, escolhida ao acaso, a uma das temperaturas.

Foram feitas duas biometrias das rãs, com intervalo de 15 dias. O período experimental teve duração de 30 dias, após a adaptação.

\section{Experimento 2}

Num segundo experimento foram reduzidas as diferenças entre as temperaturas e a amplitude térmica. Os termostatos foram regulados para 24,$5 ; 26,0$; 27,$5 ; 29,0 ; 30,5$; e $32,0^{\circ} \mathrm{C}$, sorteando-se estes trata-

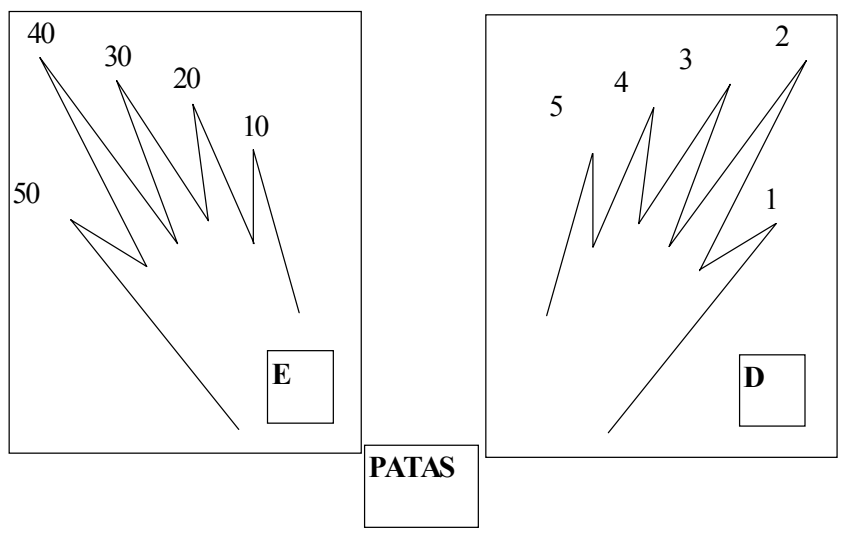

Figura 2 - Desenho esquemático das patas de uma rã ( $D$ = direita e $E$ = esquerda), com indicação dos números correspondentes a cada dedo.

Figure 2 - Schematic drawing of a frog leg $(D=$ right and $E=$ left $)$, with indication of each finger number.

mentos entre as estufas.

Um lote de trezentas rãs com peso médio inicial de 19,97 $\pm 2,69 \mathrm{~g}$ foi marcado e distribuído em 12 gaiolas, para um período de 15 dias de adaptação, à temperatura de $25,0^{\circ} \mathrm{C}$. Após a adaptação, foram selecionadas 180 rãs de peso uniforme (descartandose os extremos) e distribuídas aleatoriamente nas 12 gaiolas (quinze em cada).

A ração, tendo em vista o pequeno porte das rãs, foi triturada e umedecida com $40 \%$ de seu peso em água, para depois se misturar às larvas e servir. Foram realizadas duas biometrias com intervalo de 15 dias entre elas.

\section{Experimento 3}

Foi marcado um lote de 300 rãs com peso médio de 95,31 $\pm 8,46$ g e comprimento médio de 106,25 \pm $4,25 \mathrm{~mm}$, e distribuído em dez baias climatizadas, com fotoperíodo de 12/12 horas (L/E) e temperatura de $26,0^{\circ} \mathrm{C} \pm 1,0^{\circ} \mathrm{C}$, para recuperação do estresse da marcação e cicatrização.

Descartando-se os extremos, foram selecionadas as duzentas e quatro rãs mais uniformes, distribuindose aleatoriamente dezessete em cada gaiola, nas seis estufas. Os tratamentos foram aplicados de acordo com delineamento inteiramente casualizado, em um fatorial $3 \times 2 \times 2$, com três fotoperíodos (8/16, 12/12 e 16/8 horas de luz/horas de escuridão - L/E), duas temperaturas $\left(26,0\right.$ e $\left.29,0^{\circ} \mathrm{C}\right)$, com duas gaiolas por estufa.

Foram realizadas nove biometrias com intervalos de 10 a 11 dias entre elas. A partir da terceira 
biometria ficaram dez rãs por gaiola, após o sacrifício, para avaliação do desenvolvimento do aparelho reprodutivo. A partir da sétima biometria, restaram seis rãs por gaiola.

\section{Resultados e Discussão}

No Experimento 1, após a primeira quinzena, verificou-se diferença significativa entre os efeitos dos tratamentos $(\mathrm{P} \leq 0,01)$ sobre o ganho de peso e o crescimento das rãs; o mesmo foi verificado no final do experimento. Os dados de ganho de peso e de crescimento (y), em função da temperatura (x), ajustaram-se a modelos quadráticos (Figuras 3 e 4).

O máximo de ganho de peso estimado, ao final de 30 dias, foi $24,89 \mathrm{~g}$, à temperatura de $27,9^{\circ} \mathrm{C}$, sendo o melhor crescimento estimado em $11,49 \mathrm{~mm}$, a $28,4^{\circ} \mathrm{C}$. A faixa de temperatura na qual a Rana catesbeiana apresentou o melhor desempenho confirma a revisão de BRATTSTROM (1979) e contraria a recomendação de FONTANELLO et al. (1993), uma vez que se verificaram os piores desempenhos nos tratamentos com temperaturas de 32,0 e $35,0^{\circ} \mathrm{C}$, e a $35,0^{\circ} \mathrm{C}$ as rãs perderam peso e até morreram, confirmando as previsões de CARLSTEN et al. (1983).

Verificou-se diferença significativa entre os efeitos de gaiolas. Considerando que o calor se eleva por

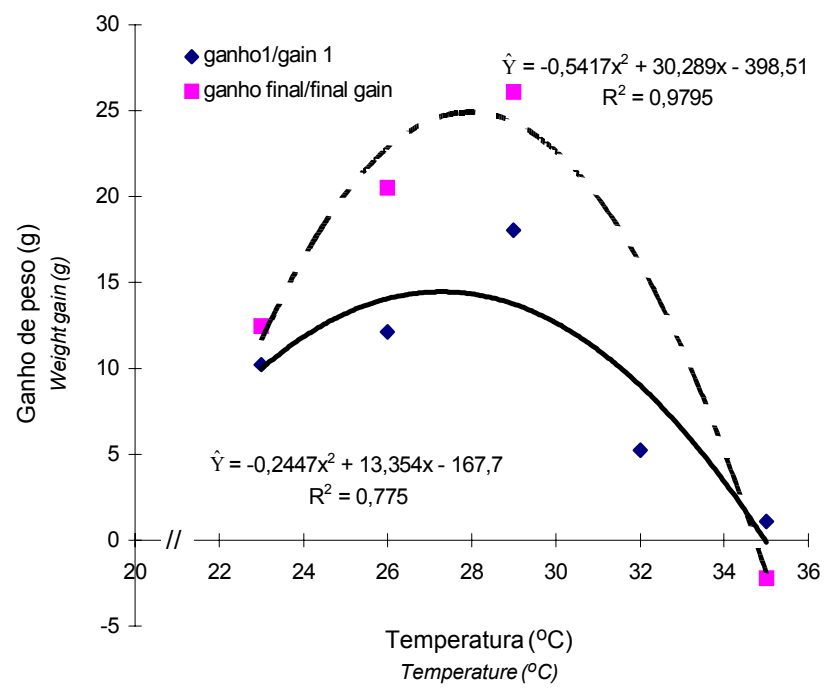

Figura 3 - Estimativa do ganho de peso da rã-touro, em relação à temperatura ambiente.

Figure 3 - Estimate of bull-frog weight gain in function of the environment temperature. convecção, nas gaiolas de cima (série 1) a temperatura tendeu a se elevar mais que nas gaiolas de baixo (série 2), prevalecendo as condições dos tratamentos nas gaiolas da série 1, mais perto dos sensores dos termostatos. Selecionando-se os resultados obtidos nas gaiolas da série 1 , verificaram-se efeitos significativos $(\mathrm{P} \leq 0,01)$ da temperatura sobre o ganho de peso e o crescimento das rãs. Os dados ajustaram-se a modelos quadráticos, representados graficamente nas Figuras 5 e 6, respectivamente, para ganho de peso e crescimento (y), em função da temperatura ambiente (x). Analisando-se apenas os dados das gaiolas da série 1, estimou-se que os melhores desempenhos ocorreram nas temperaturas de 27,6 e $28,2^{\circ} \mathrm{C}$, respectivamente, $24,42 \mathrm{~g}$ de ganho de peso e $11,03 \mathrm{~mm}$ de crescimento. As rãs, à temperatura de $35^{\circ} \mathrm{C}$, tiveram o pior desempenho e a $23^{\circ} \mathrm{C}$, menor ganho que a $29,0^{\circ} \mathrm{C}$.

No Experimento 2, com rãs de menor porte (peso médio inicial de 19,96 $\pm 2,69 \mathrm{~g}$ ), o ganho de peso, tanto no primeiro período experimental (de 15 dias) como no final, foi sempre influenciado de forma significativa pelas temperaturas testadas $(\mathrm{P} \leq 0,01)$.

Ficou evidente que os extremos de temperatura testados se localizam fora da faixa de conforto térmico das rãs, com os piores desempenhos no tratamento com temperatura de $24,5^{\circ} \mathrm{C}$ e tendência de redução no

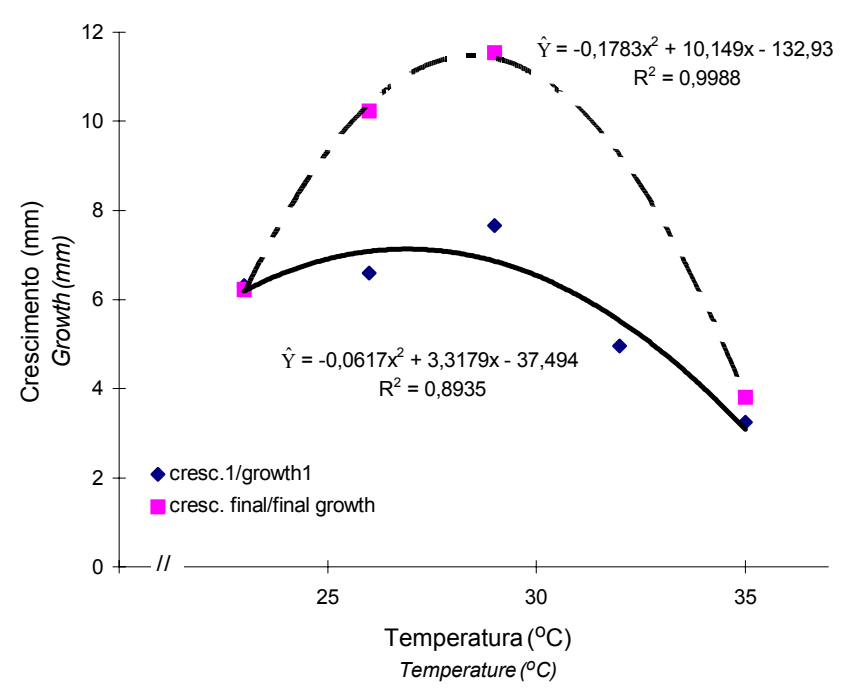

Figura 4 - Estimativa do crescimento de rã-touro, em relação à temperatura ambiente.

Figure 4 - Estimate of bull-frog growth in function of the environment temperature. 
Rev. bras. zootec.

ganho a partir de $30,5^{\circ} \mathrm{C}$, confirmando os resultados do Experimento 1. Os dados de ganho de peso e crescimento (y) ajustaram-se a modelos quadráticos, em função da temperatura (x) (Figuras 7 e 8). Estimaram-se melhores ganhos de peso a $30,1^{\circ} \mathrm{C}$ (média de 31,28 g em 30 dias) e melhor crescimento a $29,7^{\circ} \mathrm{C}$ (média de $24,81 \mathrm{~mm}$ ).

No Experimento 3, embora não tenha havido efeitos significativos das temperaturas $\left(26,0\right.$ e $\left.29,0^{\circ} \mathrm{C}\right)$

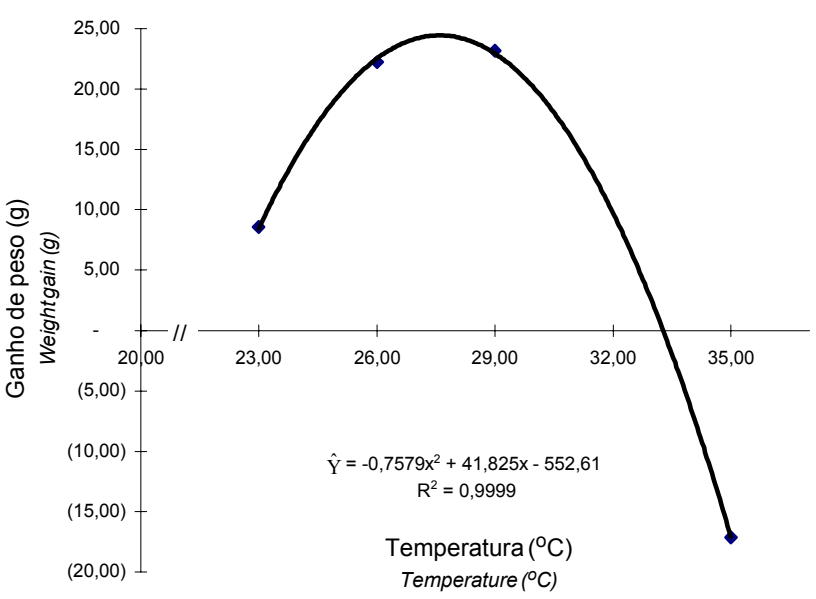

Figura 5 - Estimativa do ganho de peso de rã-touro, nas gaiolas da série 1 , em relação às diferentes temperaturas.

Figure 5 - Estimate of bull-frog weight gain, in cages of the series 1 , in function of different temperatures.

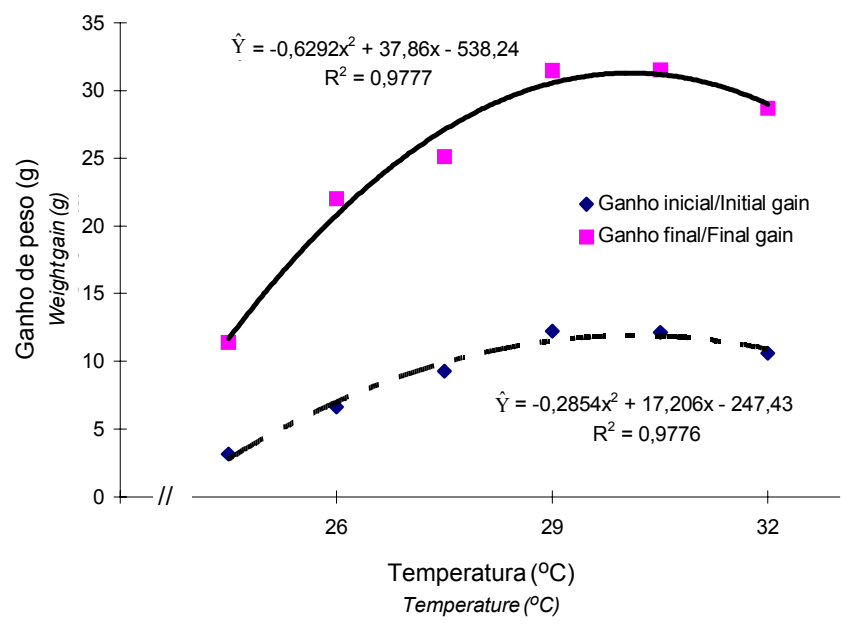

Figura 7 -Estimativa dos ganhos de peso inicial e final, para rã-touro, em relação às diferentes temperaturas.

Figure 7 - Estimate of initial and final bull-frog weight gain, in function of different temperatures. sobre ganho de peso, a análise de variância mostrou que o fotoperíodo influi significativamente $(\mathrm{P} \leq 0,01)$ no desempenho das rãs, com interação também significativa entre os efeitos de temperatura e fotoperíodo $(\mathrm{P} \leq 0,01)$ sobre o ganho de peso. A $26,0^{\circ} \mathrm{C}$, os ganhos de peso e o crescimento das rãs (y), em função do fotoperíodo $(\mathrm{x})$, ajustaram-se à quadrática, Figuras $9 \mathrm{e}$ 10. Nesta temperatura, os menores ganhos de peso foram estimados em $36,95 \mathrm{~g}$, em um fotoperíodo de

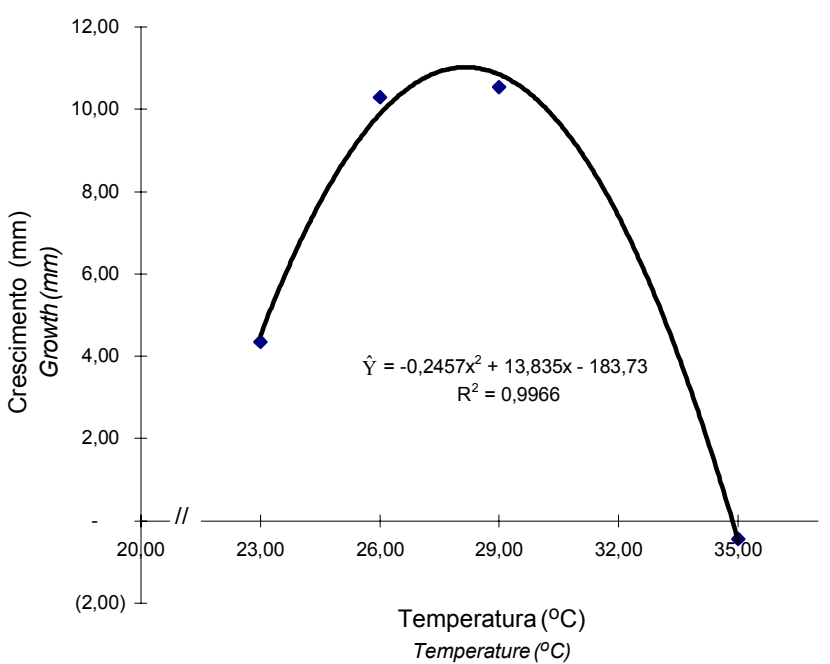

Figura 6 - Estimativa de crescimento de rã-touro, nas gaiolas da série 1, em relação às diferentes temperaturas.

Figure 6 - Estimate of bull-frog growth, in cages of the series 1, in function of different temperatures.

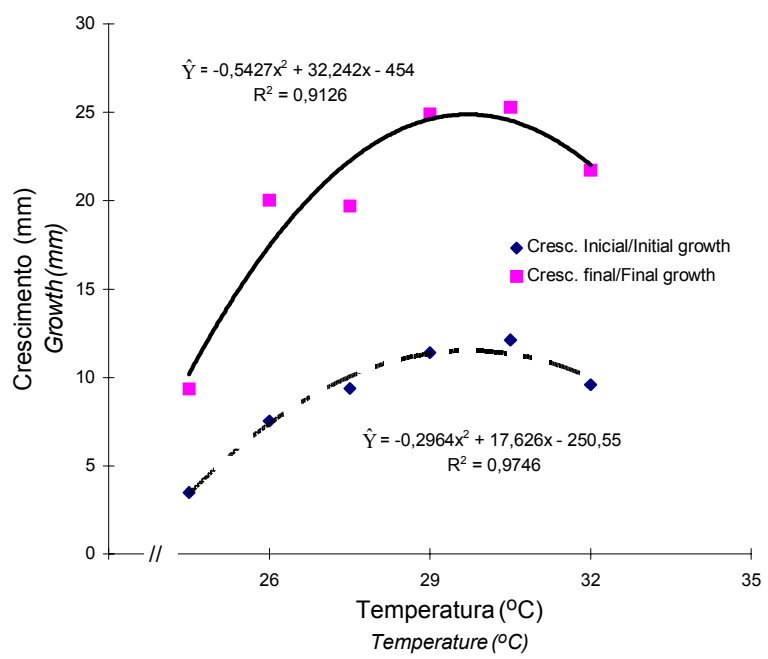

Figura 8 - Estimativa do crescimento inicial e final, para rãtouro, em relação às diferentes temperaturas.

Figure 8 - Estimate of initial and final bull-frog growth in function of different temperature. 
$10,15 / 13,85 \mathrm{~h} \mathrm{~L} / \mathrm{E}$. O crescimento mínimo estimado foi $9,41 \mathrm{~mm}$, em um fotoperíodo de 10,77/13,23 h L/E. A $29,0^{\circ} \mathrm{C}$ os diferentes fotoperíodos não influenciaram de forma significativa o ganho de peso e o crescimento.

Os pesos médios das carcaças foram influenciados de forma significativa $(\mathrm{P} \leq 0,01)$ pelas temperaturas de 26,0 e $29,0^{\circ} \mathrm{C}$, com interação entre temperatura e fotoperíodo também significativa. As carcaças das rãs, a $26,0^{\circ} \mathrm{C}$, ficaram mais pesadas (y), em função do aumento do fotoperíodo (x), de acordo com um modelo linear (Figura 11), e a $29,0^{\circ} \mathrm{C}$, variaram de peso

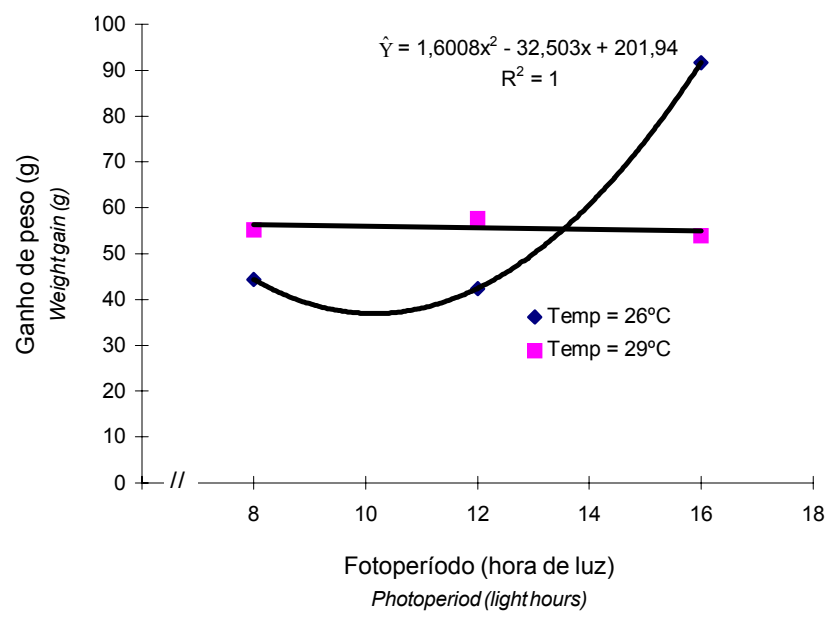

Figura 9 - Estimativa dos ganhos de peso de rã-touro em relação aos fotoperíodos, para as temperaturas de 26,0 e $29,0^{\circ} \mathrm{C}$.

Figure 9 - Estimate bull-frog weight gain in function of photoperiod, for the temperatures of 26.0 and $29.0^{\circ} \mathrm{C}$.

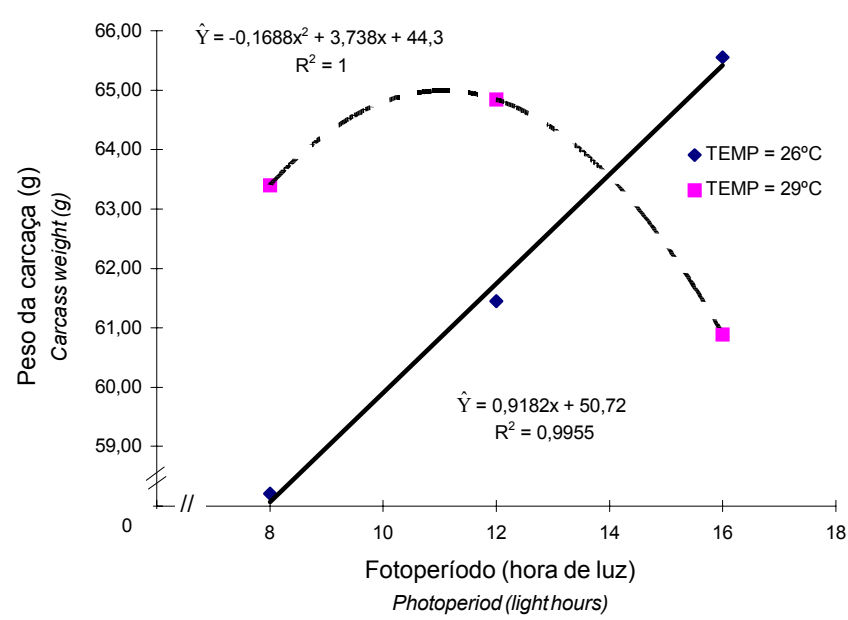

Figura 11 - Peso das carcaças de rã-touro em relação ao fotoperíodo, para as temperaturas de 26,0 e $29,0^{\circ} \mathrm{C}$.

Figure 11 - Bull-frog carcass weight in function of photoperiod for the temperatures of 26.0 and $29.0^{\circ} \mathrm{C}$. (y), em função do fotoperíodo (x), segundo um modelo quadrático (Figura 11), estimando-se maiores pesos em um fotoperíodo 11,07/12,93 h L/E (média $=64,99 \mathrm{~g}$ ).

$\mathrm{O}$ rendimento de carcaça foi significativamente influenciado pela interação entre os efeitos de temperatura e fotoperíodo $(\mathrm{P} \leq 0,05)$, que interagem de forma inversa. A variação do rendimento de carcaça (y) a 26,0 e a $29,0^{\circ} \mathrm{C}$, em função dos fotoperíodos (x) (Figura 12), explica-se por modelos quadráticos.

A interação dos efeitos de temperatura e fotoperíodo influi de forma significativa $(\mathrm{P} \leq 0,01)$ no

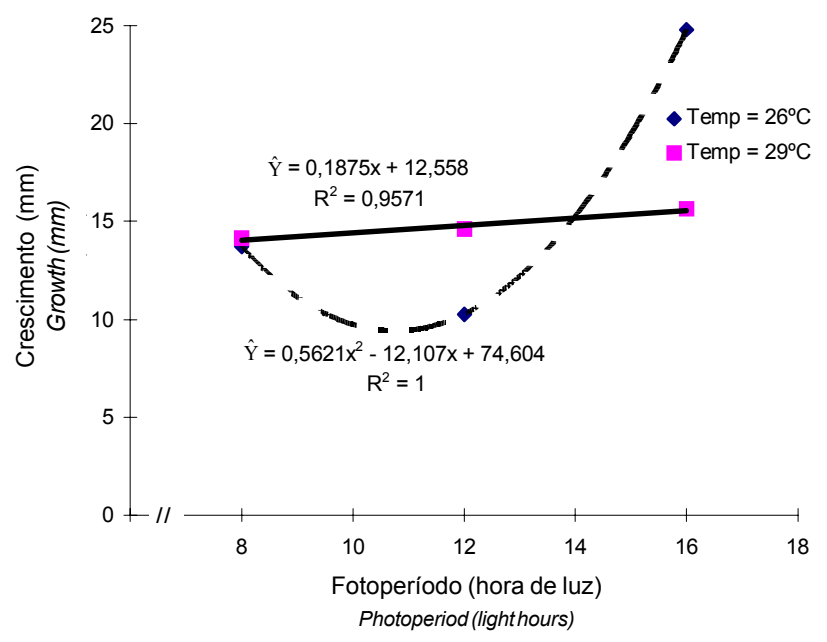

Figura 10 -Estimativa do crescimento de rã-touro, em relação aos fotoperíodos, para as temperaturas de 26,0 e $29,0^{\circ} \mathrm{C}$.

Figure 10 - Estimate of bull-frog growth in function of photoperiod, for the temperatures of 26.0 and $29.0^{\circ} \mathrm{C}$

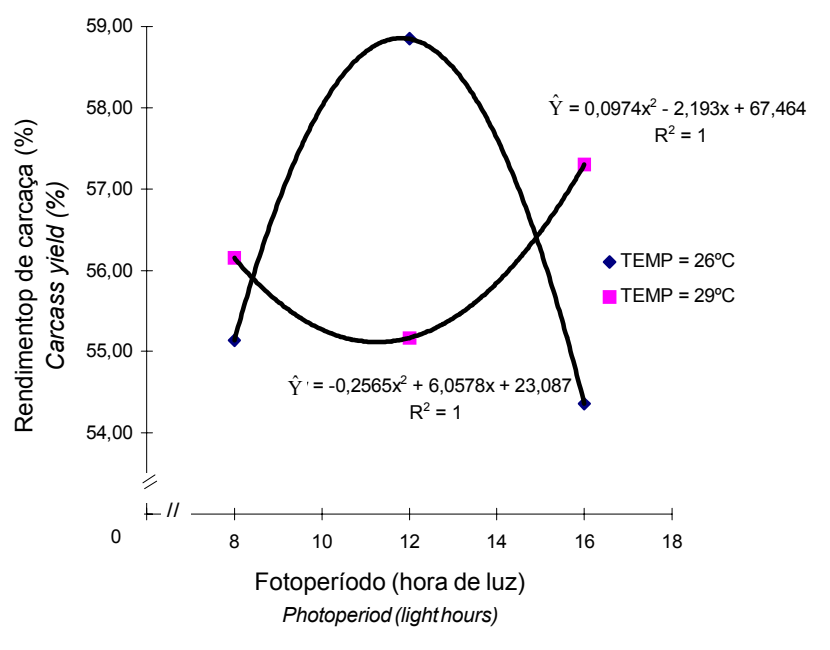

Figura 12 - Rendimento de carcaça de rã-touro, em relação ao fotoperíodo, para as temperaturas de 26,0 e $29,0^{\circ} \mathrm{C}$.

Figure 12 - Bull-frog carcass yield in function of photoperiod for the temperatures of 26.0 and $29.0^{\circ} \mathrm{C}$. 
consumo de alimentos das rãs tratadas. Não houve, contudo, diferenças significativas entre os efeitos de temperatura nem de fotoperíodo sobre o consumo de alimentos. A conversão alimentar, que também não foi influenciada nem pelas diferentes temperaturas nem pelos três fotoperíodos, individualmente, sofreu efeitos significativos $(\mathrm{P} \leq 0,05)$ da interação entre temperatura e fotoperíodo. Para uma temperatura de $26,0^{\circ} \mathrm{C}$, o consumo de alimentos (y) comportou-se de acordo com uma quadrática em função do número de horas de luz por dia (x) (Figura 13). O maior consumo $(324,39 \mathrm{~g}$ de alimento/rã), nesta temperatura, deve acontecer em fotoperíodo de 13,86/10,14 h L/E. Para a temperatura de $29,0^{\circ} \mathrm{C}$, entretanto, o consumo comportou-se de forma inversa ao observado na temperatura de $26,0^{\circ} \mathrm{C}$. A variação do consumo (y) a $29,0^{\circ} \mathrm{C}$, também, se explica por um modelo quadrático, em função do fotoperíodo (x) (Figura 12). O menor consumo, nesta temperatura, foi estimado em $259,80 \mathrm{~g}$ de alimento/rã, em fotoperíodo de 13,26/10,74 h L/E.

Tanto na temperatura de $26,0^{\circ} \mathrm{C}$ como na de $29,0^{\circ} \mathrm{C}$, a distribuição dos resultados de conversão alimentar (y), em função do fotoperíodo (x), ajustaram-se modelos quadráticos (Figura 14). O maior valor de conversão alimentar, estimada em 7,28/1 (g de alimento/g de ganho de peso), deverá acontecer a $26,0^{\circ} \mathrm{C}$, em fotoperíodo de $11,19 / 12,81 \mathrm{~h} \mathrm{~L} / \mathrm{E}$, enquanto na temperatura de $29,0^{\circ} \mathrm{C}$ o menor valor de conversão alimentar, estimado em 4,49/1, deverá ser obtido em fotoperíodo de 13,16/10,84 h L/E.

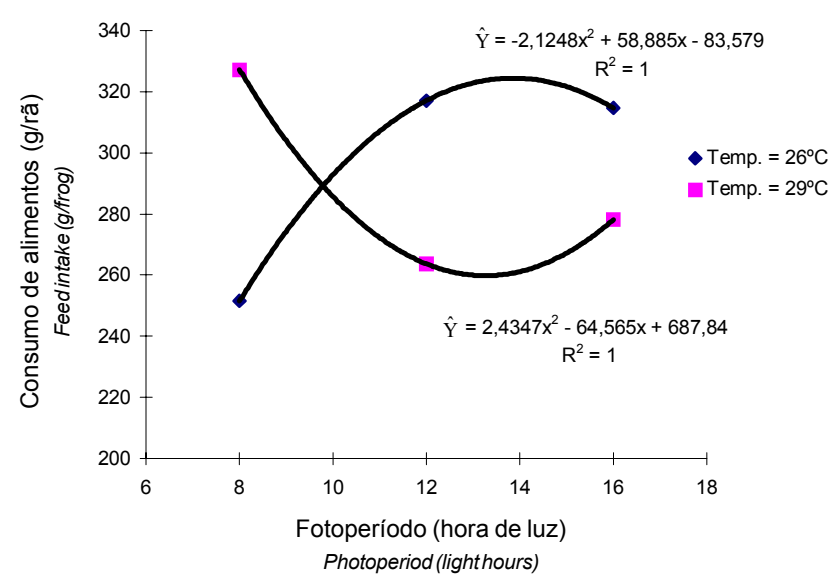

Figura 13 - Estimativa do consumo de alimentos de rãtouro, em relação ao fotoperíodo, para temperaturas de 26,0 e $29,0^{\circ} \mathrm{C}$.

Figure 13 - Estimate of bull-frog feed:gain ratio, in function of the photoperiod, for the temperatures of 26.0 and $29.0^{\circ} \mathrm{C}$.

\section{Conclusões}

A temperatura influiu no desempenho de rã-touro, avaliado em termos de ganho de peso, crescimento corporal, consumo de alimentos e conversão alimentar.

$\mathrm{O}$ rendimento de carcaça foi influenciado pela interação dos efeitos de temperatura e fotoperíodo.

A temperatura de melhor conforto térmico para rã-touro em cativeiro variou em função do seu porte. Assim, para rãs com peso inicial ao redor de $100 \mathrm{~g}, \mathrm{o}$ melhor desempenho foi observado entre as temperaturas de 27,6 e $28,2^{\circ} \mathrm{C}$, enquanto, para rãs de porte inicial aproximado de $20 \mathrm{~g}$, o melhor desempenho foi observado entre as temperaturas de 29,7 e $30,1^{\circ} \mathrm{C}$.

\section{Referências Bibliográficas}

ALEIXO, R.C., LIMA, S.L., AGOSTINHO, C.A. 1984. Criação da mosca doméstica para suplementação alimentar de rãs. Viçosa, MG: UFV, Imprensa Universitária. 11p. (Informe Técnico, 46).

BRADFORD, D.F. 1984. Temperature modulation in a highelevation Amphibian, Rana muscosa. Copeia, 4:966-976.

BRATTSTROM, B.H. 1979. Amphibiam temperature regulation studies in the field and laboratory. Amer. Zool., 19(único):345-356.

CARLSTEN, A., ERICSON, L.E., POUPA, O., WINELL, S. 1983. Heart lesions in the frog at high environmental temperature. Comparative Biochemistry and Physiology, 76A(3):583-591.

EUCLIDES, R.F. 1983. Sistema para Análises Estatísticas e Genéticas. Manual de utilização do SAEG. Viçosa: UFV. 57p.

FIGUEIREDO, M. R. C. Influência dos fatores ambientais sobre o desempenho da rã-touro (Rana catesbeiana Shaw, 1802) em Gaiolas. Viçosa, MG: UFV, 1996. 149p. Tese (Doutorado em Zootecnia) - Universidade Federal de Viçosa, 1996.

FIGUEIREDO, M.R.C., MANGIALARDO, R. R. Confinamento e engorda de rã-touro (Rana catesbeiana SHAW, 1802) em gaiolas. I. Densidade de estocagem. In: ENCONTRO NACIONAL DE RANICULTURA - ENAR, 7, 1992, Rio de Janeiro. Anais ... Rio de Janeiro, RJ: ARERJ, 1992. p.97-102.

FONTANELLO, D., WIRZ, R.R., SOARES, H.A. et al. 1993. Comparação de quatro sistemas de engorda de rãs-touro (Rana catesbeiana Shaw, 1802): tanque-ilha, confinamento, anfigranja e gaiolas. 1. Desenvolvimento ponderal; 2. Custo operacional. Bol. Inst. Pesca, 20(único).

LIMA, S.L., AGOSTINHO, C.A. 1984. Técnicas e propostas para alimentação de rãs. Viçosa, MG: UFV, 11p. (Informe técnico 50).

LIMA, S.L., AGOSTINHO, C.A. 1992. A tecnologia de criação de rãs. Viçosa, MG: UFV, Impr. Univ. 168p.

MARTOF, B.S. 1953. Territorialy in the green frog, Rana clamitans. Ecology, 34(1):166-174.

MILLER, K., ZOGHBY, G.M. 1986. Thermal acclimation of locomotor performance in Anuran Amphibians. Can. J. Zool., 64:1956-1960.

WOLLMUTH, L.P., CRAWSHAW, L.I., FORBES, R.B. et al. 1987. Temperature selection during development in a Montane Anuran species, Rana cascadae. Physiological Zoology, 60(4):472-480.

Recebido em: 21/08/98

Aceito em: 11/12/98 